\title{
Lithium-Associated Kidney Microcysts
}

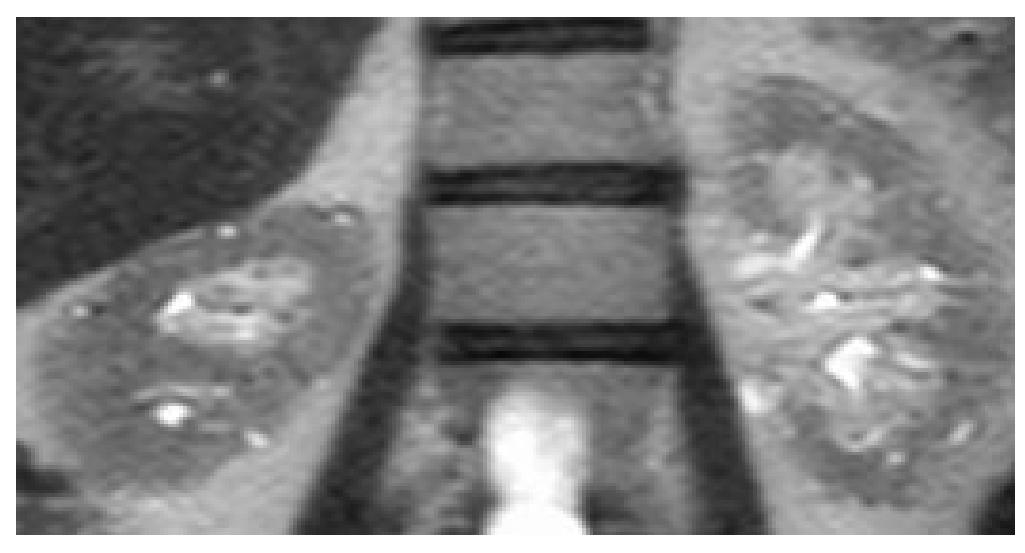

A

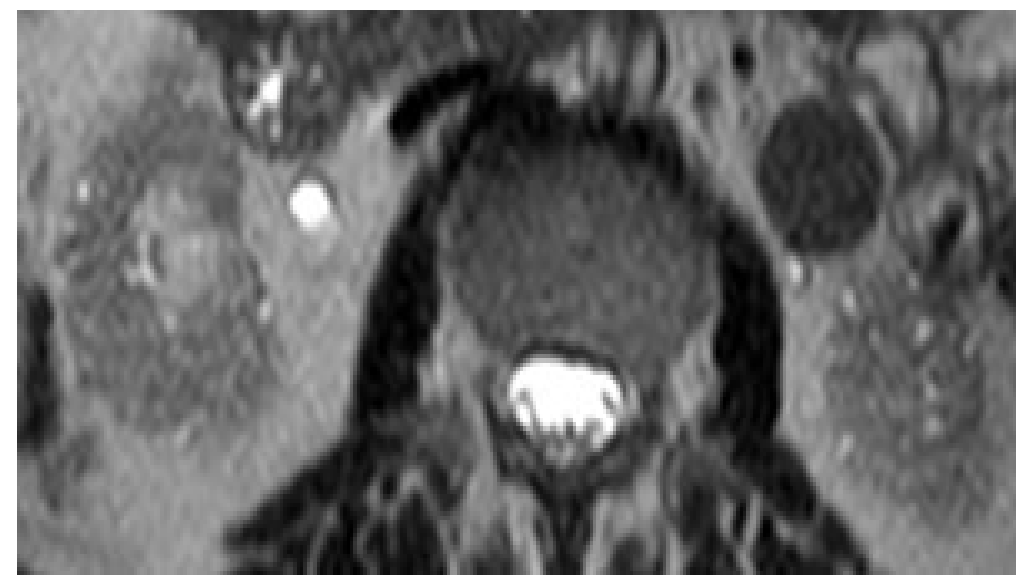

FIGURE. Magnetic resonance (MR) images of the kidney in a 76-year-old woman with chronic kidney disease (CKD) Stage IV associated with previous lithium treatment for over 30 years. (A) Coronal and (B) axial half-Fourier acquisition single-shot turbo spin-echo (HASTE) T2-weighted images (TR/TE, 1000/56; flip angle, 150 degrees) obtained with fat saturation showing multiple hyperintense microcysts in the cortical and medullary region.

Jennifer Tuazon ${ }^{1}$, David Casalino ${ }^{2}$, Ehteshamuddin Syed ${ }^{1}$, and Daniel Batlle ${ }^{1, *}$

${ }^{1}$ Division of Nephrology and Hypertension and ${ }^{2}$ Division of Radiology, Northwestern University Feinberg School of Medicine, Chicago

E-mail: d-batlle@northwestern.edu

Received June 29, 2008; Revised August 13, 2008; Accepted August 13, 2008; Published August 31, 2008

Long-term lithium therapy is associated with impairment in concentrating ability and, occasionally, progression to advanced chronic kidney disease from tubulointerstitial 
nephropathy. Biopsy findings in patients with lithium-induced chronic tubulointerstitial nephropathy include tubular atrophy and interstitial fibrosis interspersed with tubular cysts and dilatations. Recent studies have shown that cysts are seen in $33-62.5 \%$ of the patients undergoing lithium therapy. MR imaging is highly capable of defining renal morphological features and has been demonstrated to be superior to US and CT scan for the visualization of small renal cysts. The microcysts are found in both cortex and medulla, particularly in the regions with extensive atrophy and fibrosis, and can be multiple and bilateral. They tend to be sparse and do not normally exceed 1-2 $\mathrm{mm}$ in diameter. The renal microcysts in the image here reported are subtle, but consistent with lithium-induced chronic nephropathy. An MRI of the kidneys provides noninvasive evidence that strengthens the diagnosis of lithium-induced nephropathy.

KEYWORDS: lithium, kidney disease, nephropathy, cysts, MRI

\section{REFERENCES}

1. Boron, R., Gaviria, M., and Batlle, D.C. (1987) Prevalence, pathogenesis and treatment of renal dysfunction associated with chronic lithium therapy. Am. J. Kidney Dis. 10(5), 329-345.

2. Batlle, D.C., Von Riotte, A.B., Gaviari, M., and Grupp, M. (1985) Amelioration of polyuria by amiloride in patients receiving long-term lithium therapy. N. Engl. J. Med. 312, 409-414.

3. Naaz, P., Lerma, E.V., and Batlle, D.C. (1998) Lithium-induced renal effects. In Clinical Nephrotoxins - Renal Injury from Drugs and Chemicals. De Broe, M.E., Porter, G.A., Bennett, W.M., and Verpooten, G.A., Eds. Kluwer Academic, Dordrecht. pp. 383-395.

4. Farres, M.T., Ronco, P., Saadoun, D., Remy, P., Vincent, F., Khalil, A., and Le Blanche, A.F. (2003) Chronic lithium nephropathy: MR imaging for diagnosis. Radiology 229(2), 570-574.

This article should be cited as follows:

Tuazon, J., Casalino, D., Syed, E., and Batlle, D. (2008) Lithium-associated kidney microcysts. TheScientificWorldJOURNAL 8, 828-829. DOI 10.1100/tsw.2008.112. 


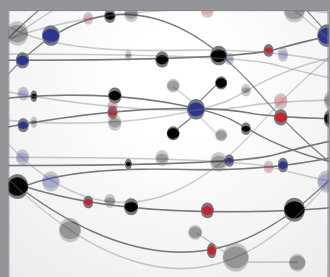

The Scientific World Journal
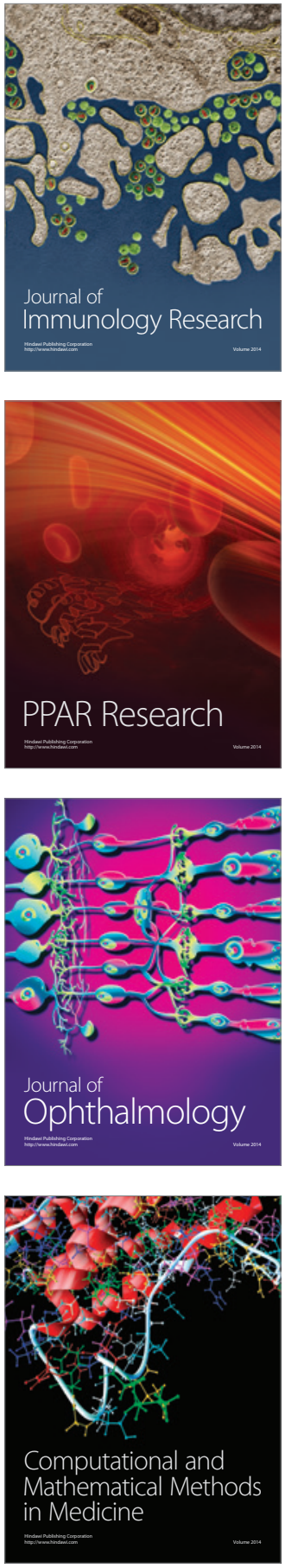

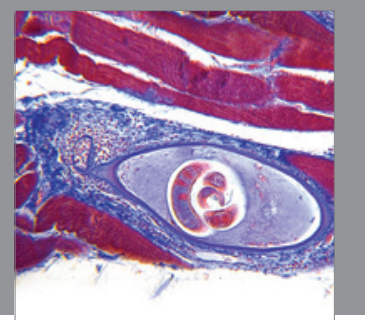

Gastroenterology

Research and Practice
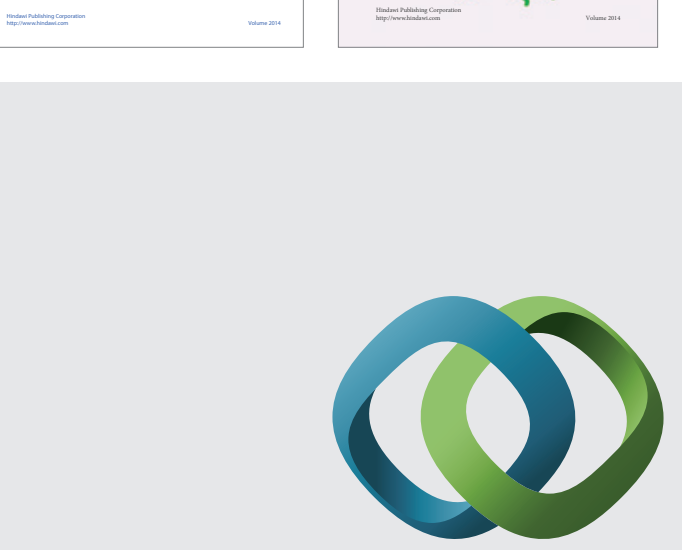

\section{Hindawi}

Submit your manuscripts at

http://www.hindawi.com
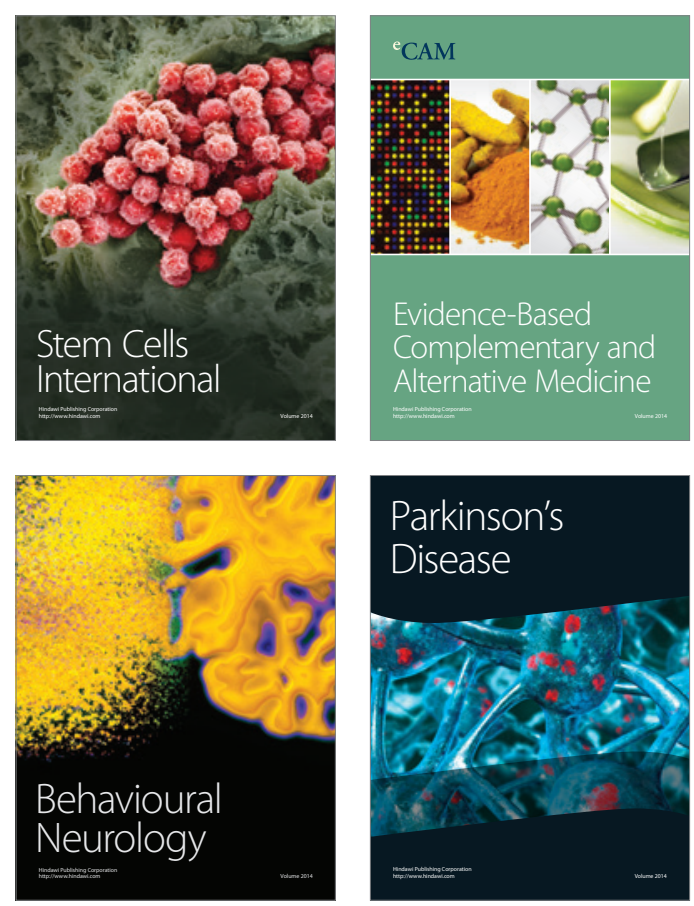

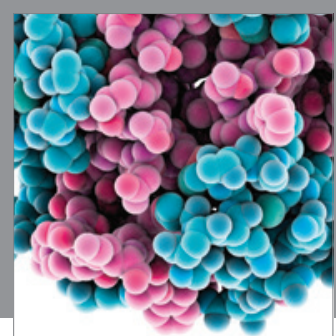

Journal of
Diabetes Research

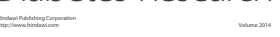

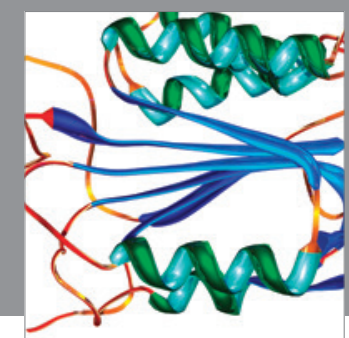

Disease Markers
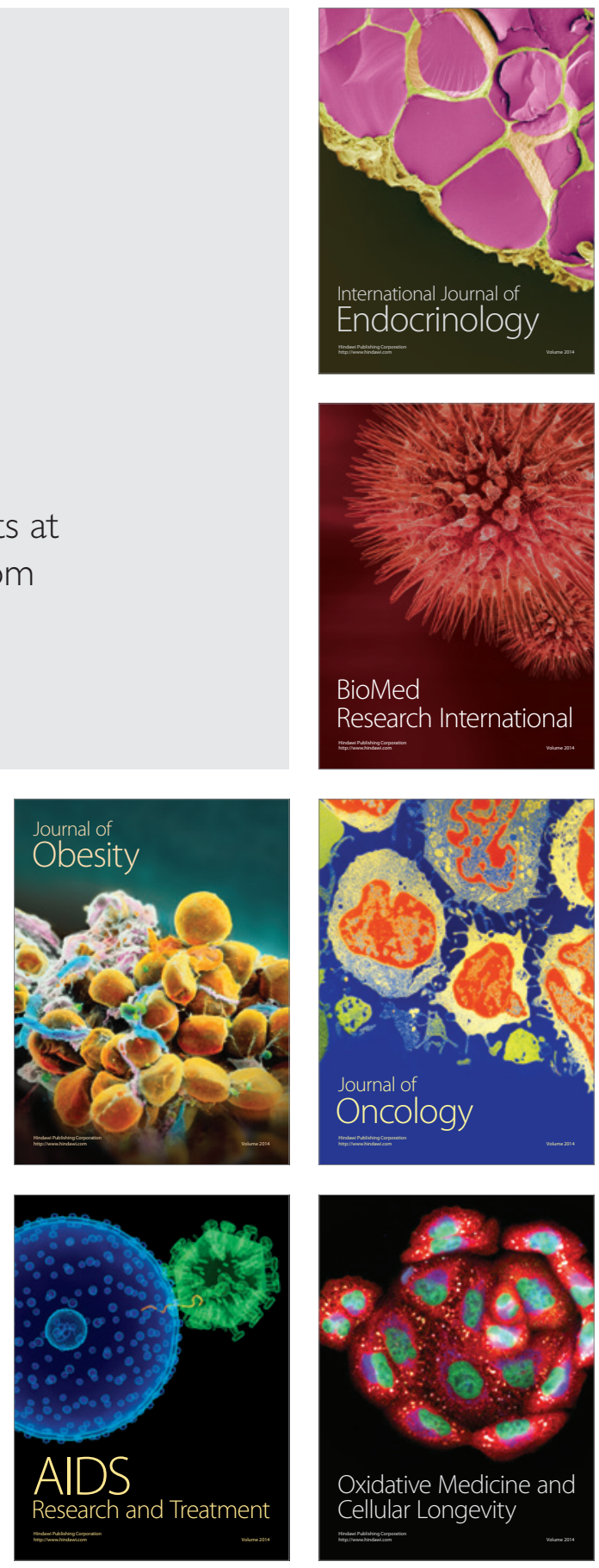